HEREDIA Z., N.A.; VIEIRA, M.C.; WEISMANN, M.; LOURENÇÃO, A.L.F. Produção e renda bruta de cebolinha e de salsa em cultivo solteiro e consorciado. Horticultura Brasileira, Brasília, v. 21, n. 3, p. 574-577, julho-setembro 2003.

\title{
Produção e renda bruta de cebolinha e de salsa em cultivo solteiro e consorciado
}

\author{
Néstor A. Heredia Z. ${ }^{1}$; Maria do Carmo Vieira ${ }^{1}$; Martin Weismann ${ }^{2}$; André L.F. Lourenção ${ }^{2}$ \\ UFMS, C. Postal 533, 79804-970 Dourados-MS, E-mail: nheredia @ceud.ufms.br; ${ }^{1}$ Bolsista de Produtividade em Pesquisa do CNPq; \\ ${ }^{2}$ Alunos da UFMS
}

\begin{abstract}
RESUMO
Foram estudadas a cebolinha 'Todo Ano' e a salsa 'Lisa', em cultivos solteiro e consorciado, arranjadas no delineamento experimental de blocos casualizados, com três tratamentos e oito repetições. A propagação da cebolinha foi por mudas e a da salsa por sementes. Na colheita, feita aos 90 dias após o início da propagação, nas duas espécies, foram avaliadas a altura das plantas, diâmetro das touceiras e produções de massas fresca e seca das plantas. Também foram avaliados diâmetro e número de perfilhos das plantas de cebolinha e a altura do corte das plantas de salsa. As médias de altura das plantas da cebolinha $(33,50 \mathrm{~cm})$ e da salsa $(27,11 \mathrm{~cm})$, do diâmetro dos perfilhos da cebolinha $(0,42 \mathrm{~cm})$ e da altura do corte nas plantas da salsa $(6,41 \mathrm{~cm})$ não apresentaram efeito dos tratamentos. As maiores médias do diâmetro das touceiras foram obtidas nas plantas sob cultivo solteiro, com diferenças de $6,13 \mathrm{~cm}$ na cebolinha e de $2,85 \mathrm{~cm}$ na salsa, em relação àquelas sob consórcio. As plantas da cebolinha consorciadas com a salsa tiveram aumento significativo de 0,54 milhões de perfilhos ha ${ }^{-1}$ em relação àquelas sob cultivo solteiro. As produções médias das plantas da cebolinha e da salsa sob cultivo solteiro tiveram, respectivamente, mais $1,32 \mathrm{e}$ $2,42 \mathrm{t} \mathrm{ha}^{-1}$ de massa fresca e 0,20 e $0,24 \mathrm{t} \mathrm{ha}^{-1}$ de massa seca em relação àquelas sob consórcio. As razões de área equivalente para o consórcio cebolinha e salsa foram de 1,41 e 1,50 ao considerar as produtividades de massas frescas e secas, respectivamente. A renda bruta total mostrou que o consórcio cebolinha-salsa foi melhor, com aumentos por hectare de $25,06 \%$ (R $\$ 7.830,00$ ) e de $74,93 \%$ (R\$ $16.740,00)$, quando relacionado com a renda da cebolinha ou da salsa em cultivo solteiro, respectivamente.
\end{abstract}

Palavras-chave: Allium fistulosum, Petroselinum crispum, arranjo de plantas, produtividade, retorno econômico.

\begin{abstract}
Bunching onion and parsley yield and gross income in monocropping and inter-cropping system

'Todo ano' bunching onion and 'Lisa' parsley were studied in mono and inter-cropping system arranged in a randomized complete block experimental design with three treatments and eight replications. Bunching onion was propagated by cuttings and parsley by seeds. Both crops were harvested 90 days after the beginning of propagation. Plant height, copse diameter and dried and fresh mass yield were evaluated. Also diameter and number of shoots of bunching onion plants and height of parsley plants were evaluated. Averages of bunching onion $(33.50 \mathrm{~cm})$ and parsley $(27.11 \mathrm{~cm})$ height, of bunching onion shoot diameters $(0.42 \mathrm{~cm})$ and of cut height of parsley $(6.41 \mathrm{~cm})$ plants were not affected by treatments. The greatest average of copse diameter was obtained in plants under mono-cropping system, with differences of $6.13 \mathrm{~cm}$ for bunching onion and $2.85 \mathrm{~cm}$ for parsley in relation to those under inter-cropping system. Bunching onion plants inter-cropped with parsley had a significant increase of 0.54 millions of shoots ha ${ }^{-1}$ in relation to those under mono-cropping system. Average yield of bunching onion and parsley plants under mono-cropping system presented an increase of 1.32 and $2.42 \mathrm{t} \mathrm{ha}^{-1}$ of fresh mass and of 0.20 and $0.24 \mathrm{t} \mathrm{ha}^{-1}$ of dried mass, respectively, in relation to those in inter-cropping system. Land equivalent ratios for bunching onion and parsley inter-cropping system were 1.41 and 1.50 considering dried and fresh mass yield, respectively. Total gross income showed that bunching onion intercropped was better with increases of $25.06 \%(\mathrm{R} \$ 7,830.00)$ and $74.93 \%$ ( $\$$ \$ 16.740.00) per hectare when related to gross income of bunching onion or parsley in mono-cropping system, respectively.
\end{abstract}

Keywords: Allium fistulosum, Petroselinum crispum, plant arrangements, yield, income.

\section{(Recebido para publicação em 17 de maio de 2002 e aceito em 19 de maio de 2003)}

\begin{abstract}
A cebolinha comum (Allium fistulosum, L.), originária da Sibéria, e a cebolinha (Allium schoenoprasum), originária da Europa continental, são condimentos, muito apreciados pela população e cultivadas em quase todos os lares brasileiros. A planta é considerada perene, apresenta folhas cilíndricas e fistulosas, com 0,30 a $0,50 \mathrm{~m}$ de altura, coloração verde-escura, tendendo para o glauco em $A$. fistulosum; produz pequeno bulbo cônico, envolvido por uma película rósea, com perfilhamento e formação de
\end{abstract}

touceira. As cultivares mais conhecidas são Todo Ano, Futonegui e Hossonegui (Embrater, 1980; Cotia, 1987; Ferreira et al., 1993; Makishima, 1993; Filgueira, 2000). Embora a planta de cebolinha suporte frios prolongados e existam cultivares que resistam bem ao calor, tendo poucas restrições para o seu plantio em qualquer época do ano, a faixa de temperatura ideal para o cultivo fica entre 8 e $22^{\circ} \mathrm{C}$, ou seja, em condições amenas. Portanto, o perfilhamento é maior nos plantios de fevereiro a julho nas regiões produtoras do Brasil
(Cotia, 1987; Makishima, 1993; Filgueira, 2000). A colheita da cebolinha inicia-se entre 55 e 60 dias após o plantio ou entre 85 e 100 dias após a semeadura, quando as folhas atingem de 0,20 a $0,40 \mathrm{~m}$ de altura.

A salsa (Petroselinum crispum) é uma das espécies de hortaliças que não atinge sua importância pelo volume ou valor de comercialização mas pela utilização comercial como condimento. A planta produz mais em solos areno-argilosos, com alto teor de matéria orgânica, boa fertilidade e $\mathrm{pH}$ entre 5,8 e 6,8. 
A primeira colheita é feita entre 50 e 90 dias após a semeadura, quando as plantas atingirem cerca de 10 a $15 \mathrm{~cm}$ de altura.

Tanto na cebolinha como na salsa, o rebrotamento é aproveitado para novos cortes, podendo um cultivo ser explorado por dois a três anos, principalmente quando são conduzidos em condições de clima ameno. Na comercialização para consumo ao natural, elas aparecem sós ou formando um conjunto popularmente chamado de cheiro-verde. Nos últimos anos, a cebolinha tem sido cultivada para o abastecimento de agroindústrias de conserva (Ferreira et al., 1993).

A associação/consorciação de culturas é um sistema de cultivo utilizado há séculos pelos agricultores (Müeller et $a l ., 1998)$ e é praticado amplamente nas regiões tropicais (Srinivasan \& Ahlawat, 1990), sobretudo por pequenos agricultores. Isto porque, ao utilizarem nível tecnológico mais baixo, procuram maximizar os lucros (Vieira, 1989), buscando melhor aproveitamento dos insumos e da mão-de-obra, geralmente da própria família, em capinas, aplicações de defensivos e outros tratos culturais (Vieira, 1989; Caetano et al., 1999). Paschoal (1994) cita que o cultivo intercalar de salsão com repolho tem ajudado a repelir borboletas cujas lagartas danificam as folhas.

$\mathrm{O}$ aumento da produtividade por unidade de área é uma das razões mais importantes para se cultivar duas ou mais culturas no sistema de consorciação, que no caso de ser feito com hortaliças permite melhor aproveitamento da terra e de outros recursos disponíveis, resultando em maior rendimento econômico (Silva, 1983; Sullivan, 1998). Em estudo realizado por Tolentino Júnior (2001), em Dourados, sobre a produção da mandioquinhasalsa 'Amarela de Carandaí' consorciada com alface 'Grand Rapids' e beterraba 'Tal Top Early Wonder', concluiuse que as plantas das três espécies apresentaram produtividade superior em monocultivo, em todos os componentes avaliados. Considerando-se a produção total de raízes e a de raízes comercializáveis respectivamente, a razão de área equivalente para o consór- cio mandioquinha-beterraba foi de 1,07 e 0,87 e para mandioquinha-alface foi 1,3 e 1,1 .

$\mathrm{Na}$ literatura não foram encontrados relatos sobre o consórcio cebolinha e salsa. Com o presente trabalho estudouse a produtividade e o retorno econômico da cebolinha e da salsa, conduzidas em cultivo solteiro ou consorciadas.

\section{MATERIAL E MÉTODOS}

O trabalho foi desenvolvido na horta da UFMS, em Dourados, entre 29/8/01 e 27/11/01, em Latossolo Vermelho distroférrico, de textura argilosa, com as seguintes características químicas: 5,5 de $\mathrm{pH}$ em $\mathrm{CaCl}_{2} ; 34,0 \mathrm{~g} \mathrm{dm}^{-3}$ de M.O; 36,0 $\mathrm{mg} \mathrm{dm}^{-3}$ de P; 6,6; 56,0 e 22,6 $\mathrm{mmol} \mathrm{dm}^{-3}$ de $\mathrm{K}$, Ca e $\mathrm{Mg}$, respectivamente. O clima da região, segundo a classificação de Köppen (Mato Grosso do Sul, 1990) é Mesotérmico Úmido; do tipo Cwa, com temperaturas e precipitações médias anuais variando de 20 a $24^{\circ} \mathrm{C}$ e 1250 a $1500 \mathrm{~mm}$, respectivamente.

Foram estudadas a cebolinha Todo Ano e a salsa Lisa, cada uma em cultivo solteiro e consorciado, compondo três tratamentos, arranjados no delineamento experimental de blocos casualizados, com oito repetições. A análise estatística foi realizada isoladamente para cada espécie, utilizando dois tratamentos (cultivo solteiro e consorciado) e oito repetições. As parcelas tiveram área total de 3,0 $\mathrm{m}^{2}$ (1,5 $\mathrm{m}$ de largura $\mathrm{x} 2,0 \mathrm{~m}$ de comprimento) e a área útil de 2,16 $\mathrm{m}^{2}$ (1,08 $\mathrm{m}$ de largura $\mathrm{x} 2,0 \mathrm{~m}$ de comprimento). A parcela da cebolinha, tanto em cultivo solteiro como no consorciado, tinha cinco linhas $(21,6 \mathrm{~cm}$ entre linhas) com vinte plantas por linha (10 $\mathrm{cm}$ entre plantas), perfazendo população de 330.000 plantas ha-1. A parcela da salsa tinha quatro linhas, tanto em cultivo solteiro (27 cm entre linhas) como no consorciado $(21,6 \mathrm{~cm}$ entre linhas), com 40 plantas por linha $(5 \mathrm{~cm}$ entre plantas), perfazendo população de 528.000 plantas ha-1 . No cultivo consorciado, as cinco linhas da cebolinha foram alternadas com as quatro linhas da salsa.

A propagação da cebolinha foi por mudas e a da salsa por sementes. As mudas foram preparadas no dia anterior ao do plantio. Posteriormente, foram separados os perfilhos e feita a toilette do material propagativo com a separação e eliminação das raízes. Também foram realizados cortes na parte foliar, para deixar aproximadamente $5 \mathrm{~cm}$ de pseudocaule e eliminação das bainhas secas. O plantio consistiu no enterrio vertical das mudas, deixando-se ao descoberto aproximadamente $3 \mathrm{~cm}$ do pseudocaule. As irrigações foram feitas por aspersão com o intuito de manter o solo "sempre úmido" (após observações subjetivas) e que induziu a turnos de rega a cada dois dias. O controle das plantas infestantes foi feito com auxílio de enxadas nas entrelinhas e com arranquio manual dentro das linhas.

Na colheita, feita aos 90 dias após o início da propagação, mediante o corte das touceiras das plantas, rente ao solo para a cebolinha e imediatamente acima das brotações novas para a salsa, foram avaliadas a altura das plantas, diâmetro das touceiras e produções de massas frescas e secas das plantas. Também foram avaliados diâmetro e número de perfilhos das plantas de cebolinha e a altura do corte das plantas de salsa. Os dados foram submetidos à análise de variância, utilizando o teste $\mathrm{F}$ a $5 \%$ de probabilidade.

O consórcio foi avaliado utilizando a expressão da razão de área equivalente (RAE) proposto por Caetano (1999), a saber: $\mathrm{RAE}=\mathrm{Cc} . \mathrm{Cs}^{-1}+\mathrm{Sc} . \mathrm{Ss}^{-1}$, onde, respectivamente, $\mathrm{Cc}$ e $\mathrm{Sc}$ correspondem a produções da cebolinha e da salsa em consorciação e Cs e Ss correspondem a produções da cebolinha e da salsa em cultivo solteiro. A validação do consórcio foi realizada mediante a determinação da renda bruta. Para isso, foram comprados cinco maços de cebolinha e de salsa, em dois locais de venda no varejo, e determinadas as massas frescas (variação de 56,1 a 81,0 g e média de $63,6 \mathrm{~g}$ para a cebolinha e de $63,1 \mathrm{a}$ $67,4 \mathrm{~g}$ e média de $64,9 \mathrm{~g}$ para a salsa). Os custos dos maços no varejo variaram de $\mathrm{R} \$ 0,40$ a $\mathrm{R} \$ 0,50$ mas, segundo os vendedores, o preço pago aos produtores foi de $\mathrm{R} \$ 0,25$ por maço de cebolinha ou de salsa. Posteriormente, efetuaram-se as conversões por hectare para número de maços e renda bruta, por cultivo e total, para o produtor. 
Tabela 1. Produção da cebolinha Todo Ano em cultivo solteiro e consorciado com salsa. Dourados, UFMS, 2001.

\begin{tabular}{|c|c|c|c|c|c|c|}
\hline \multirow[t]{2}{*}{ Cultivo } & \multirow[t]{2}{*}{$\begin{array}{c}\text { Altura de } \\
\text { plantas }(\mathrm{cm})\end{array}$} & \multicolumn{2}{|c|}{ Diâmetro $(\mathrm{cm})$} & \multirow{2}{*}{$\begin{array}{l}\text { Número } \\
\text { perfilhos } \\
\text { (milhões) }\end{array}$} & \multicolumn{2}{|c|}{$\begin{array}{c}\text { Massa das plantas sem } \\
\text { raízes }\left(t \mathrm{ha}^{-1}\right)\end{array}$} \\
\hline & & Touceira & Perfilho & & Fresca & Seca \\
\hline Solteiro & $33,21 \mathrm{a}$ & $27,89 \mathrm{a}$ & $0,44 \mathrm{a}$ & $2,24 b$ & $7,95 \mathrm{a}$ & $0,88 a$ \\
\hline Consorciado & 33,79 a & $21,76 \quad b$ & $0,40 \mathrm{a}$ & $2,78 a$ & $6,63 \mathrm{~b}$ & $0,68 \quad b$ \\
\hline C.V. & 9,31 & 12,74 & 10,04 & 9,28 & 15,94 & 8,39 \\
\hline
\end{tabular}

Médias seguidas pelas mesmas letras nas colunas não diferem pelo teste $\mathrm{F}$, a $5 \%$ de probabilidade.

Tabela 2. Produção da salsa Lisa em cultivo solteiro e consorciado com cebolinha. Dourados, UFMS, 2001.

\begin{tabular}{lllcccc}
\hline \multirow{2}{*}{ Cultivo } & \multicolumn{2}{c}{ Altura $(\mathbf{c m})$} & \multirow{2}{*}{$\begin{array}{c}\text { Diâmetro da } \\
\text { touceira }(\mathbf{c m})\end{array}$} & \multicolumn{2}{c}{ Massa das plantas $\left(\mathbf{t ~ h a}^{-1}\right)$} \\
\cline { 2 - 3 } \cline { 7 - 8 } & Planta & Corte & & Fresca & Seca \\
\hline Solteiro & $28,41 \mathrm{a}$ & $6,48 \mathrm{a}$ & & $29,88 \mathrm{a}$ & $5,80 \mathrm{a}$ & $0,90 \mathrm{a}$ \\
Consorciado & $25,80 \mathrm{a}$ & $6,34 \mathrm{a}$ & & $27,03 \quad \mathrm{~b}$ & $3,38 \mathrm{~b}$ & $0,66 \quad \mathrm{~b}$ \\
\hline C.V. & 13,74 & 7,53 & 8,67 & 25,37 & 14,54 \\
\hline
\end{tabular}

Médias seguidas pelas mesmas letras nas colunas não diferem pelo teste $\mathrm{F}$, a $5 \%$ de probabilidade.

Tabela 3. Renda bruta do produtor, considerando a produção de massa fresca da cebolinha Todo Ano e da salsa Lisa em cultivo solteiro e consorciado. Dourados, UFMS, 2001.

\begin{tabular}{|c|c|c|c|c|c|}
\hline \multirow{2}{*}{ Cultivo } & \multirow{2}{*}{ Espécie } & \multirow{2}{*}{$\begin{array}{c}\text { Massa } \\
\left(\mathrm{t} \mathrm{ha}^{-1}\right)\end{array}$} & \multirow{2}{*}{$\begin{array}{l}\text { Maços* } \\
\left(\mathrm{n}^{\circ} \mathrm{ha}^{-1}\right)\end{array}$} & \multicolumn{2}{|c|}{ Renda bruta $\left(\mathrm{R} \$ 1.000 \mathrm{ha}^{-1}\right)^{* *}$} \\
\hline & & & & Por cultivo & Total \\
\hline \multirow{2}{*}{ Solteiro } & Cebolinha & 7,95 & 125.000 & 31,25 & 31,25 \\
\hline & Salsa & 5,80 & 89.368 & 22,34 & 22,34 \\
\hline \multirow[t]{2}{*}{ Consorciado } & Cebolinha & 6,63 & 104.245 & 26,06 & \multirow{2}{*}{39,08} \\
\hline & Salsa & 3,38 & 52.080 & 13,02 & \\
\hline
\end{tabular}

* Divisão da massa obtida no trabalho pelas médias de massa dos maços, sendo 63,6 g para cebolinha e 64,9 g para salsa. ** Considerouse $\mathrm{R} \$ 0,25$ o preço pago ao produtor por maço de cebolinha ou de salsa.

\section{RESULTADOS E DISCUSSÃO}

Não houve diferença significativa para as médias de altura das plantas de cebolinha $(33,50 \mathrm{~cm})$ e de salsa $(27,11$ $\mathrm{cm})$, do diâmetro dos perfilhos de cebolinha $(0,42 \mathrm{~cm})$ e da altura do corte nas plantas de salsa $(6,41 \mathrm{~cm})$ (Tabelas 1 e 2). Isso indica que as plantas apresentam taxas de crescimento e morfologia bem características, com padrão de resposta dependente do componente genético (Heredia Z., 1988). Os resultados obtidos para altura de plantas indica que, provavelmente, não se utilizaram as populações máximas combinadas que poderiam ter interferido na expressão desse caráter, por isso, não houve efeito da competição interespecífica no consórcio. Por outro lado, as médias do diâmetro das touceiras de cebolinha e de salsa foram influenciadas significativamente pelo tipo de cultivo. As maiores médias foram obtidas nas plantas sob cultivo solteiro, com diferenças de $6,13 \mathrm{~cm}$ na cebolinha e de $2,85 \mathrm{~cm}$ na salsa, em relação àquelas sob consórcio. Esses resultados mostram relação com a hipótese de Larcher (2000), sobre os sistemas ecológicos terem capacidade de auto-regulação, com base no equilíbrio das relações de interferência, ou seja, as plantas de uma comunidade vegetal formada por espécies diferentes estão sujeitas a diversos tipos de interações. $\mathrm{Na}$ maioria dos casos, a interação é notada pela redução da produtividade das culturas (Silva, 1983).

As plantas de cebolinha consorciadas com a salsa tiveram aumento signi- ficativo de 0,54 milhões de perfilhos ha-1 em relação àquelas sob cultivo solteiro (Tabela 1). Isso pode ter relação com a forma de interação em cultivos associados que pode promover aumentos na produtividade, apesar de ser pouco comum, e que talvez seja causada pela excreção de hormônios estimuladores de crescimento; no entanto, esse estímulo foi citado apenas para algumas variedades de arroz intercultivadas (Whatley \& Whatley, 1982).

As produções médias das plantas de cebolinha e de salsa sob cultivo solteiro tiveram, respectivamente, mais 1,32 e $2,42 \mathrm{t} \mathrm{ha}^{-1}$ de massa fresca e 0,20 e 0,24 $\mathrm{t} \mathrm{ha} \mathrm{a}^{-1}$ de massa seca em relação àquelas sob consórcio (Tabelas 1 e 2). Esses resultados vêm de encontro com a hipótese de que a partição dos fotoassimilados, sobretudo, é função do genótipo e das 
relações fonte-dreno, onde a eficiência de conversão fotossintética, dentre outros fatores, pode ser alterada pelas condições de solo, clima e estádio fisiológico da cultura (EMBRAPA, 1996; Fancelli \& Dourado Neto, 1996). Também podem indicar que as plantas solteiras tiveram melhor adaptabilidade, normalmente relacionadas com a manutenção da eficiência na absorção ou no uso da água, dos nutrientes e do $\mathrm{CO}_{2}$. A menor produção das plantas de cebolinha sob consórcio deve ter relação com a presença das plantas de salsa, que podem ter induzido perda da capacidade produtiva devido à competição entre as raízes, que exploravam o solo à mesma profundidade (Silva, 1983), ou porque as folhas responderam diferencialmente à competição por luz (Whatley \& Whatley, 1982).

A RAE para o consórcio cebolinha e salsa, considerando as produtividades de massa fresca das culturas, foi de 1,41 $(\mathrm{RAE}=\mathrm{Cc} / \mathrm{Cs}+\mathrm{Sc} / \mathrm{Ss}=6,63 / 7,95+$ $3,38 / 5,8=1,41)$ e ao considerar a massa seca, a RAE foi de 1,5. Esses resultados mostram que o consórcio foi efetivo. Ao relacionar a renda bruta (Tabela 3), observou-se que para o produtor o consórcio cebolinha-salsa foi melhor, por ter induzido incrementos monetários por hectare de $25,06 \%$ ( R $\$ 7830,00)$ ou de $74,93 \%$ ( R $\$ 16.740,00)$, quando relacionado com a renda da cebolinha ou da salsa em cultivo solteiro, respectivamente. Os valores obtidos para RAE e para a renda bruta concordam com Silva (1983) e Sullivan (1998), quando citam que o aumento da produtividade por unidade de área é uma das razões mais importantes para se cultivar duas ou mais culturas no sistema de consorciação, porque permite melhor aproveitamento do uso da terra e de outros recursos disponíveis, resultando em maior rendimento econômico.

\section{AGRADECIMENTOS}

Ao CNPq, pelas bolsas concedidas e à FUNDECT-MS, pelo apoio financeiro.

\section{LITERATURA CITADA}

CAETANO, L.C.S.; FERREIRA, J.M.; ARAÚJO, M. Produtividade da alface e cenoura em sistema de consorciação. Horticultura Brasileira, Brasília, v. 17, n. 2, p. 143-146, 1999.

COOPERATIVA AGRÍCOLA DE COTIA. Manual de cultivo das principais hortaliças. Cotia: Cooperativa Central, Departamento de Sementes e Mudas, 1987. 104 p.

EMPRESA BRASILEIRA DE ASSISTÊNCIA TÉCNICA E EXTENSÃO RURAL. Manual técnico de Olericultura. Rio de Janeiro, Brasília, 1980. 98 p. (Manuais, 28)

EMPRESA BRASILEIRA DE PESQUISA AGROPECUÁRIA. Recomendações técnicas para o cultivo do milho. 2.ed. Brasília: EMBRAPA-SPI, 1996. 204 p.

FANCELLI, A.L.; DOURADO NETO, D. Milho: fisiologia da produção. In: SEMINÁRIO SOBRE FISIOLOGIA DA PRODUÇÃO E MANEJO DE ÁGUAE DE NUTRIENTES NA CULTURA DO MILHO DE ALTA PRODUTIVIDADE, 1996. Palestras.... Piracicaba: ESALQ/USP-POTAFÓS, 1996. p. 1-29.

FERREIRA, M.E.; CASTELLANE, P.D.; CRUZ, M.C.P. Nutrição e adubação de hortaliças. In: ANAIS DO SIMPÓSIO SOBRE NUTRIÇÃO E ADUBAÇÃO DE HORTALIÇAS, Jaboticabal, 1990. Anais... Piracicaba: POTAFOS, 1993. p. 473-476.

FILGUEIRA, F.A.R. Novo manual de olericultura: agrotecnologia moderna na produção e comercialização de hortaliças. Viçosa: UFV, 2000. 402 p.
HEREDIA Z., N.A. Curvas de crescimento de inhame (Colocasia esculenta (L.) Schott), considerando cinco populações, em solo seco e alagado. Viçosa, 1988.95 p. (Tese doutorado), UFV.

LARCHER, W. Ecofisiologia vegetal. São Carlos: RiMa Artes e Textos, 2000. 531 p.

MAKISHIMA, N. Aspectos gerais da cultura da salsa. Informe Agropecuário, Belo Horizonte, v. 10, n. 120, p. 78-80, 1984.

MAKISHIMA, N. O cultivo de hortaliças. Brasília: EMBRAPA-CNPH: EMBRAPA-SPI, 1993. 116 p. (Coleção plantar, 4)

MATO GROSSO DO SUL. Secretaria de Planejamento e Coordenação Geral. Atlas Multireferencial. Campo Grande, 1990. 28 p.

MÜELLER, S.; DURIGAN, J.C.; BANZATTO, D.A.; KREUZ, C.L. Épocas de consórcio de alho com beterraba perante três manejos do mato sobre a produtividade e o lucro. Pesquisa Agropecuária Brasileira, Brasília, v. 33, n. 8, p. 1361-1373, 1998.

PASCHOAL, A.D. Produção orgânica de alimentos: agricultura sustentável para os séculos XX e XXI. Piracicaba. 1991. 191 p.

SILVA, N.F. Consórcio de hortaliças. In: Heredia, M.C.V; Burba, J.L; Casali, V.W.D. "coord". Seminários de Olericultura. Viçosa: UFV, v. VII, p. 1-19, 1983.

SRINIVASAN, A.; AHLAWAT, I.P.S. Growth and yield responses of short duration pigeonpea to intercropping with mungbean and sorghum, and to phosphate fertilization. 1990. Disponível: Site Regional Science Institute. Disponível em $<\mathrm{http}$ / /www.vtt.co.jp/staff/ ancha/jagcs.htm>. Acesso em 15/09/2000.

SULLIVAN, P. Intercropping principles and production practices. 1998. Site: Apropriate Technology Transfer for Rural Areas - ATTRA. Disponível em <http://www.attra.org/attra-pub/ intercrop.html\#abstract.>. Acesso em 15/09/2000. TOLENTINO JÚNIOR, C.F. Produção $d a$ mandioquinha-salsa sob competição da alface $e$ beterraba. Dourados, 2001.40 p. (Tese mestrado). UFMS

VIEIRA, C. O feijão em cultivos consorciados. Viçosa: Imprensa Universitária, 1989. 134 p.

WHATLEY, J.M.; WHATLEY, F.R. A luz e a vida das plantas. São Paulo: Editora Pedagógica e Universitária Ltda. 1982. 101 p. 